\title{
Keanekaragaman Kupu-Kupu di Bendungan Ulung Peliang Kecamatan Tamako Kepulauan Sangihe, Sulawesi Utara
}

\section{(Diversity of Butterflies in Ulung Peliang Dam, Tamako District, Sangihe Islands, North Sulawesi}

\author{
Sabatini Hengkengbala ${ }^{*}$, Roni Koneri, Deidy Y. Katili \\ Program Studi Biologi, FMIPA Universitas Sam Ratulangi, Jl. Kampus Unsrat, Bahu, Manado, \\ Sulawesi Utara 95115 \\ *Email korespondensi: sabatini632@gmail.com
}

(Article History: Received 02 Maret 2019; Revised 20 April 2020; Accepted 06 Mei 2020)

\begin{abstract}
ABSTRAK
Kupu-kupu merupakan serangga yang termasuk dalam ordo Lepidoptera. Serangga tersebut memiliki peranan yang penting dalam suatu ekosistem yaitu mempertahankan keseimbangan ekosistem dan memperkaya keanekaragaman hayati di alam. Penelitian ini bertujuan untuk menganalisis keanekaragaman kupu-kupu di kawasan Bendungan Ulung Peliang, Kecamatan Tamako, Kabupaten Kepulauan Sangihe, Sulawesi Utara. Teknik pengambilan sampel menggunakan metoda transek. Pengambilan sampel dilakukan pada tiga tipe habitat yaitu habitat pinggir bendungan, hutan dan kebun. Pada masing-masing habitat dibuat transek dengan panjang 300m. Pengambilan sampel kupukupu dilakukan sepanjang garis transek menggunakan sweepnet. Komposisi kupu-kupu yang diperoleh terdiri dari 5 famili, 30 spesies dan 463 individu. Famili yang paling banyak ditemukan jumlah spesies dan individunya adalah Nymphalidae. Spesies yang memiliki kelimpahan tertinggi adalah Junonia hedonia intermedia dan Eurema tominia. Analisis keanekaragaman didapatkan bahwa indek kekayaan, indek keanekaragaman dan indek kemerataan spesies kupu-kupu tertinggi ditemukan pada habitat kebun, sedangkan kelimpahan spesies tertinggi terdapat pada habitat pinggir bendungan. Kata kunci: Keanekaragaman; kupu-kupu; Bendungan Ulung Peliang; Kepulauan Sangihe
\end{abstract}

\section{ABSTRACT}

Butterflies are insects that are included in the order Lepidoptera. Theses insects have an important role in ecosystem that is to maintain the balance of the ecosystem and enrich the biodiversity in nature. This study aims to analyze the diversity of butterflies in the area of Ulung Peliang Dam, Tamako District, Sangihe Islands Regency, North Sulawesi. The sampling technique used the transect method. Sampling has been carried out in three types of habitats namely dam, forest and garden habitat. Each transect has been made with a length of $300 \mathrm{~m}$. Butterfly sampling was carried out along the transect line using. The composition of butterflies that habve been obtained consisted of 5 families, 30 species and 463 individuals. The most abundant family with a number of species and individuals is Nymphalidae. Species that have the highest abundance are Junonia hedonia intermedia and Eurema tominia. Diversity analysis found that the highest wealth index, diversity index and evenness species of butterfly species were found in the garden habitat, while the highest species abundance was in the dam edge habitat.

Keywords: Diversity; butterfly; Ulung Peliang Dam; Sangihe Islands.

\section{PENDAHULUAN}

Kawasan Bendungan Ulung Peliang (Upel) merupakan bendungan dari Sungai Ulung Peliang yang terletak di Desa Ulung Peliang Kecamatan Tamako, Kepulauan Sangihe, Sulawesi Utara. Bendungan Upel berfungsi sebagai Pembangkit Listrik
Tenaga Air (PLTA) yang dikelola oleh PLN area Tahuna Kabupaten Sangihe. Kawasan ini juga dijadikan sebagai objek wisata bagi masyarakat Kepulauan Sangihe. Kawasan sekitar bendungan Upel memiliki berbagai tipe ekosistem seperti hutan, perkebunan dan sungai. Ekosistem 
tersebut dihuni oleh berbagai flora dan fauna yang terdapat pada ekosistem tersebut adalah kupu-kupu.

Kupu-kupu merupakan serangga yang termasuk dalam ordo Lepidoptera atau serangga bersayap sisik. Kupu-kupu memiliki peranan yang penting dalam suatu ekosistem. Peran ini meliputi nilai ekonomi, ekologi, estetika, pendidikan, konservasi dan budaya. Peran ekologis kupu-kupu dapat mempertahankan keseimbangan ekosistem dan memperkaya keanekaragaman hayati di alam. Kupukupu berperan sebagai polinator pada proses penyerbukan bunga, sehingga membantu perbanyakan tumbuhan secara alami dalam suatu ekosistem (Bambang dan Muhamad 2013).

Keanekaragaman kupu-kupu di suatu tempat berbeda dengan tempat yang lain. Faktor yang mempengaruhi keberadaan kupu-kupu pada suatu habitat sangat erat kaitannya dengan faktor lingkungan baik faktor biotik maupun abiotik.

Perbedaan faktor inilah yang menyebabkan jenis kupu-kupu di setiap habitat pulau juga berbeda-beda. Keberadaan spesies pada suatu habitat tidak terlepas dari kemampuan distribusi dan adaptasi spesies tersebut. Indonesia menduduki urutan kedua didunia dalam hal kekayaan spesies kupu-kupu (Rhopalocera) dengan jumlah spesies lebih dari 2000 spesies (Amir et al. 2003).

Penyebaran kupu-kupu di dunia sangat luas yakni hampir semua tipe habitat jika terdapat tumbuhan yang menjadi sumber pakan dan shelter. Diantara faktor-faktor yang membatasi penyebaran kupu-kupu adalah geologi, kondisi ekologi yang cocok dan sebaran tanaman inang yang menjadi pakan kupu-kupu dewasa maupun pada fase larva (Amir et al., 2003). Kupu-kupu bahkan dapat ditemukan hampir semua tipe habitat asalkan memiliki tumbuhan inang yang sesuai dengan jenis kupu-kupu tersebut (Peggie dan Amir, 2006). Penyebaran kupu-kupu juga ditemukan pada berbagai tipe habitat di kawasan
Bendungan Upel Desa Ulun Peliang Kecamatan Tamako Kepualaun Sangihe.

Kurangnya penelitian dan publikasi tentang keanekaragaman kupu-kupu di Kawasan Bendungan Upel Kecamatan Tamako Kepulauan Sangihe, menyebabkan penyebaran kupu-kupu serta jenisnya belum diketahui pasti. Padahal data ini sangat diperlukan dalam konservasi kupukupu di Kawasan Bendungan Upel. Penelitian ini bertujuan untuk menganalisis keanekaragaman kupu-kupu di kawasan Bendungan Ulung Peliang, Kecamatan Tamako, Kabupaten Kepulauan Sangihe, Sulawesi Utara

\section{METODE}

\section{Waktu dan Tempat Penelitian}

Penelitian ini dilaksanakan di kawasan Bendungan Ulung Peliang, Kecamatan Tamako, Kabupaten Kepulauan Sangihe, Sulawesi Utara. Pengambilan data dilakukan bulan September 2019 sampai Oktober 2019. Habitat yang dijadikan sebagai tempat pengambilan sampel adalah hutan sekunder, kebun dan pinggir bendungan Upel. Habitat hutan sekunder memiliki berbagai macam pohon yang banyak jumlahnya. Vegetasi yang terdapat pada habitat ini yaitu Swietenia mahagoni (mahoni), Ficus benjamina (beringin), Bambusa sp. (bambu), dan Poacea (rumput-rumputan). Habitat kebun terdapat berbagai jenis tumbuhan baik yang ditanam manusia maupun yang tumbuh liar. Vegetasi yang terdapat di sekitar habitat ini yaitu Musaceae (pisang), Syzigium aromaticum (cengkeh), Citrus sp (Jeruk), Cocos nucifera (kelapa), Canarium vulgare (Kenari), dan berbagai macam spesies Poacea (rumput-rumputan). Habitat di pinggir bendungan terdapat berbagai macam pohon dan jenis tumbuhan berbunga, semak, dan rerumputan. Habitat bendungan terdapat aliran sungai.

\section{Metode Pengambilan Sampel}

Teknik pengambilan sampel menggunakan metoda transek. Pada setiap tipe habitat dibuat tiga garis transek 
dengan panjang $300 \mathrm{~m}$. Pengambilan sampel dimulai dari jam 08:00-14:00 WITA. Penempatan transek pada setiap habitat dilakukan secara Purposive Random Sampling. Pengambilan sampel dilakukan sepanjang garis transek dengan menggunakan jaring serangga. Pengambilan sampel dilakukan setiap bulan selama dua bulan. Kupu-kupu yang dikoleksi hanya satu spesimen setiap spesies, bila ditemukan tiap spesies yang sama jenis, maka kupu-kupu tersebut akan dilepaskan kembali. Kupu-kupu yang menjadi sampel disimpan dalam amplopamlop kertas papilot berbentuk segitiga yang berukuran $30 \mathrm{~cm}$ x $20 \mathrm{~cm}$. Proses identifikasi dan klasifikasi spesimen kupukupu menggunakan buku identifikasi Peggie (2011; 2014; 2016), dan VanWright dan de Jong (2003).

\section{Analisis Data}

Analisis data yang dilakukan dalam penelitian ini meliputi: Indeks kekayaan spesies (S), Indeks keanekaragaman spesies (H'), dan Indeks kemerataan spesies (E) (Magurran 1988), dengan rumus sebagai berikut:

\section{Indeks keanekaragaman}

Keterangan:

$$
\mathrm{H}^{\prime}=-\sum_{i=1}^{S}(P i \ln P i)
$$

$\mathrm{Pi}=\mathrm{n} / \mathrm{N}$

$\mathrm{H}^{\prime}=$ Indeks keanekargaman Shannon-Wiener

$\mathrm{ni}=$ Jumlah individu setiap spesies

$\mathrm{N}=$ Jumlah individu seluruh

\section{Indeks kekayaan spesies (R)}

Keterangan :

$$
\mathrm{R}=\frac{S-1}{\ln \cdot N}
$$

R: Indeks Richness

$\mathrm{S}$ : Jumlah spesies

$\mathrm{N}$ : Total individu dalam pengambilan sampel.

\section{Indeks Kemerataan}

$\mathrm{E}=\mathrm{H}^{\prime} / \ln \mathrm{S}$
Keterangan:

E : Indeks kemerataan (Evenness)

H': indeks kemerataan Shannon- Wiener

$\mathrm{S}:$ Jumlah spesies $(\mathrm{n} 1, \mathrm{n} 2, \mathrm{n} 3 \ldots . .$.

\section{HASIL DAN PEMBAHASAN \\ Komposisi Spesies Kupu-Kupu}

Berdasarkan penelitian yang telah dilakukan didapatkan sebanyak 30 spesies yang termasuk dalam 21 genus dan 5 famili yaitu Nymphalidae, Papilionidae, Pieridae, Lycaenidae dan Hesperidae. Nymphalidae terdiri dari 15 spesies, Papilionidae (4 spesies), Pieridae (4 spesies), Lycaenidae (2 5 spesies), dan Hesperidae sebanyak 2 spesies (Tabel 1)

Jumlah spesies yang didapatkan baru mencapai $1,71 \%$ dari speies yang terdapat di Indonesia, dan 5,36\% dari spesies kupukupu yang terdapat di Pulau Sulawesi. Spesies kupu-kupu yang pernah dilaporkan di Indonesis memiliki jumlah kira-kira 1750 spesies kupu-kupu (Peggie, 2014), sedangkan Pulau Sulawesi terdapat 560 spesies kupu-kupu (Vane-Wright dan de Jong, 2003).

Spesies kupu-kupu yang ditemukan di kawasan Bendungan Ulung Peliang lebih sedikit dibandingkan dengan hasil penelitian yang dilakukan di Suaka Margasatwa Manembo-Nembo Sulawesi Utara sebanyak 44 spesies (Koneri dan Maabuat 2016). Hasil penelitian ini lebih banyak spesies kupu-kupu yang ditemukan dibandingkan dengan penelitian kupu-kupu di kawasan air terjun Tunan Talawaan Minahasa Utara Sulawesi Utara sebanyak 28 spesies (Pareang, 2018).

Penelitian di Gunung Manado Tua Kawasan Taman Nasional Laut Bunaken Sulawesi Utara sebanyak 29 spesies (Koneri dan Saroyo 2012). Perbedaan jumlah spesies kupu-kupu yang ditemukan pada suatu lokasi sangat bergantung pada tipe habitat, vegetasi atau tumbuhan penyusun habitat, teknik pengambilan sampel, lama pengambilan sampel dan luas lokasi pengambilan sampel. 
Tabel 1. Kelimpahan spesies kupu-kupu pada 3 tipe habitat bendungan Ulung Peliang, Kecamatan Tamako, Kepulauan Sangihe

\begin{tabular}{|c|c|c|c|c|c|c|}
\hline \multirow{2}{*}{ No } & \multirow{2}{*}{ Famili/Spesies } & \multicolumn{3}{|c|}{ Habitat } & \multirow{2}{*}{ Total } & \multirow{2}{*}{$\%$} \\
\hline & & Bendungan & Hutan & Kebun & & \\
\hline I & Nymphalidae & & & & & \\
\hline 1 & Junonia hedonia intermedia & 30 & 9 & 21 & 60 & 12,96 \\
\hline 2 & Hypolimnas bolina & 17 & 2 & 3 & 22 & 4,75 \\
\hline 3 & Parthenos sylva salentia & 14 & 3 & 3 & 20 & 4,32 \\
\hline 4 & Danaus ismare alba & 11 & 2 & 3 & 16 & 3,46 \\
\hline 5 & Euploea euporator & 5 & 0 & 10 & 15 & 3,24 \\
\hline 6 & Lasippa neriphus tawayana & 2 & 5 & 8 & 15 & 3,24 \\
\hline 7 & Euploea leucostictos westwodi & 9 & 1 & 1 & 11 & 2,38 \\
\hline 8 & Terinos clarissa & 3 & 5 & 2 & 10 & 2,16 \\
\hline 9 & Cupha arias & 2 & 2 & 5 & 9 & 1,94 \\
\hline 10 & Ideopsis juventa tontoliensis & 4 & 2 & 3 & 9 & 1,94 \\
\hline 11 & Mycalesis janardana & 1 & 2 & 6 & 9 & 1,94 \\
\hline 12 & Danaus affinitis fulgarata & 2 & 0 & 3 & 5 & 1,08 \\
\hline 13 & Idea leисопое & 1 & 2 & 0 & 3 & 0,65 \\
\hline 14 & Cyrestis acilia & 0 & 0 & 1 & 1 & 0,22 \\
\hline 15 & Nymphalidae Sp 1 & 0 & 1 & 0 & 1 & 0,22 \\
\hline II & Papilionidae & & & & & \\
\hline 16 & Graphium meyeri & 32 & 1 & 8 & 41 & 8,86 \\
\hline 17 & Papilio rumanzovia & 14 & 1 & 9 & 24 & 5,18 \\
\hline 18 & Papilio polytes & 0 & 1 & 1 & 2 & 0,43 \\
\hline 19 & Graphium agamemnon & 0 & 1 & 0 & 1 & 0,22 \\
\hline III & Pieridae & & & & & \\
\hline 20 & Eurema tominia & 67 & 32 & 34 & 133 & 28,73 \\
\hline 21 & Catopsilia pomona flava & 2 & 2 & 3 & 7 & 1,51 \\
\hline 22 & Eurema blanda & 7 & 0 & 0 & 7 & 1,51 \\
\hline 23 & Eurema hecabe & 6 & 0 & 1 & 7 & 1,51 \\
\hline IV & Lycaenidae & & & & & 0,00 \\
\hline 24 & Jamides aratus & 2 & 10 & 0 & 12 & 2,59 \\
\hline 25 & Lycaenidae Sp 1 & 7 & 0 & 0 & 7 & 1,51 \\
\hline 26 & Jamides pura & 2 & 0 & 4 & 6 & 1,30 \\
\hline 27 & Lycaenidae Sp 2 & 0 & 4 & 2 & 6 & 1,30 \\
\hline 28 & Jamides celeno & 0 & 0 & 1 & 1 & 0,22 \\
\hline V & Hesperiidae & & & & & \\
\hline 29 & Erionota thrak & 0 & 1 & 1 & 2 & 0,43 \\
\hline 30 & Potanthus chloe & 0 & 0 & 1 & 1 & 0,22 \\
\hline & Jumlah & 240 & 89 & 134 & 463 & 100,00 \\
\hline
\end{tabular}

Spesies kupu-kupu yang banyak ditemukan adalah Eurema tominia dari famili Pieridae dengan jumlah individu 133 individu $(28,73 \%)$. Spesies ini menyukai habitat basah dan biasanya terbang rendah di antara rerumputan yang hampir dekat dengan tanah. Kupu-kupu dewasa menghisap mineral pada genangan air (mudpudlling) (Peggie, 2014). Kondisi habitat bendungan sesuai dengan kelangsungan hidup Eurema tominia sehingga spesies ini ditemui di pinggir bendungan dengan jumlah yang banyak yaitu 67 individu (Tabel 1).

Spesies yang paling sedikit ditemui selama penelitian yaitu Cyrestis acilia dan Nymphalidae Sp 1 dari famili Nymphalidae dengan jumlah masing-masing satu individu. Spesies berikutnya adalah Graphium agamemnon dari famili Papilionidae, Jamides celeno dari famili Lycaenidae dan Potanthus chloe dari famili Hesperidae dengan jumlah masing-masing satu spesies. 
Spesies-spesies ini sedikit ditemui karena faktor lingkungan atau habitat yang tidak sesuai dengan keberlangsungan hidup mereka.

Famili yang paling banyak ditemukan di kawasan Bendungan Ulun Peliang yaitu Nymphalidae dengan prosentase $44,9 \%$ (Gambar 1). Nymphalidae banyak ditemukan karena famili ini memiliki jumlah spesies terbanyak dalam ordo Lepidoptera. Famili ini memiliki ukuran tubuh kecil sampai besar dengan warna dan corak sayap yang beragam. Kupu-kupu Nymphalidae memakan buah, daging bangkai, dan kotoran (Herlina 2017).

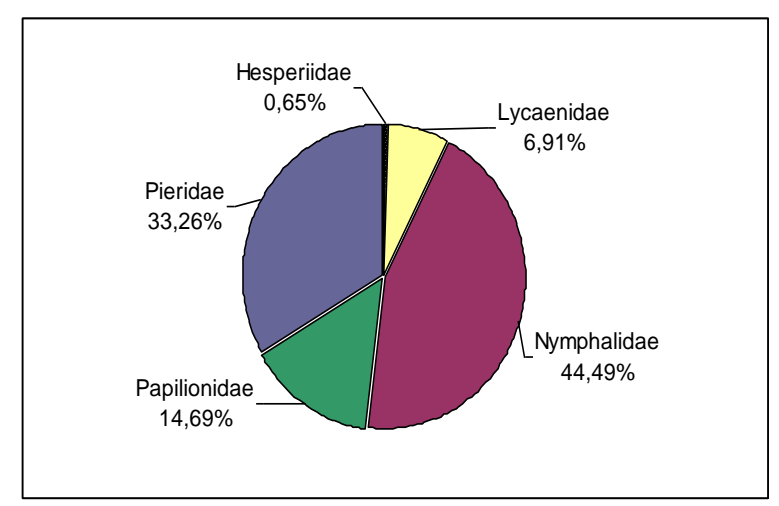

Gambar 1. Kelimpahan famili kupu-kupu yang ditemukan pada 3 tipe habitat bendungan Ulun Peliang.

Famili Nymphalidae umumnya mempunyai penyebaran yang luas, menyukai tempat yang terang, dan dapat ditemukan pada habitat kebun, hutan dan juga menyukai tempat yang busuk (Dendang 2009). Hal tersebut juga didukung karena tersedianya tumbuhan inang yang beragam untuk mendukung kehidupan famili ini, baik sebagai tempat berlindung maupun sebagai sumber makanan. Lestari (2015) melaporkan bahwa kupu-kupu Nymphalidae mempunyai tumbuhan inang yang lebih dari satu macam atau bersifat polyfag. Sifat polyfag inilah yang memungkinkan Nymphalidae dapat memenuhi kebutuhannya meskipun tidak adanya ketersediaan tumbuhan inangnya.

Tumbuhan inang dari famili Nymphalidae yaitu Annonaceae, Asteraceae, Verbenaceae, Moraceae, Rubiaceae dan
Anacardiaceae (Lamatoa, et al. 2013). Spesies tumbuhan yang banyak ditemukan di Kepulauan Sangihe seperti Ficus sp (Moraceae), Mussaenda pubescens (Rubiaceae), Garcinia sp (Fagaceae), Lantana camara (Verbenaceae), Cananga odorata (Annonaceae), Mangifera indica (Anacardiaceae), Ficus benjamina (Moraceae), Citrus sp (Rutaceae) dan Eupatorium inulifolium (Asteraceae).

Perbedaan famili yang dominan yang ditemukan di beberapa daerah karena penyebaran kupu-kupu dipengaruhi oleh sebaran tumbuhan inang dan ekologi (Amir et al. 2003; Panjaitan 2008). Famili Nymphalidae dapat dengan mudah ditemukan sepanjang musim, karena bersifat generalis dan beberapa jenis Nymphalidae tidak bergantung pada keberadaan nektar bunga saja namun kupu-kupu ini mampu mendapatkan sumber pakan dari buah yang busuk maupun urin dari satwa lainnya (Sarma et al. 2012; Sari et al. 2013).

Lycaenidae dan Hesperiidae merupakan famili yang paling sedikit ditemukan pada kawasan Bendungan Ulung Peliang. Hal ini disebabkan karena kurangnya ketersediaan pakan untuk memenuhi kebutuhan kupukupu dari kedua famili tersebut. Faktor lain yang menyebabkan famili Lycaenidae dan Hesperiidae ini sedikit ditemukan karena ukuran tubuhnya yang kecil dan sifatnya yang suka hinggap pada daun sehingga jarang teramati (Peggie 2014).

\section{Indeks Keanekaragaman Kupu-Kupu}

Indeks kekayaan spesies dan indeks keanekaragaman spesies kupu-kupu tertinggi terdapat pada habitat kebun, sedangkan yang terendah pada pinggir bendungan. Indeks kemerataan spesies tertinggi juga pada habitat kebun dan terendah pada hutan (Gambar 2).

Indeks kekayaan spesies dan indeks keanekaragaman spesies kupu-kupu tertinggi terdapat pada habitat kebun, sedangkan yang terendah pada pinggir bendungan. Indeks kemerataan spesies tertinggi juga pada habitat kebun dan terendah di hutan (Gambar 2). 
Kelimpahan kupu-kupu tertinggi pada habitat pinggir bendungan karena adanya 3 spesies dominan yang ditemukan pada habitat

tersebut yaitu Eurema tominia, Graphium meyeri dan Junonia hedonia intermedia. Dominannya ketiga spesies kupu-kupu tersebut karena habitat bendungan menjadi salah satu tempat yang disukainya karena memiliki tumbuhan yang menjadi sumber pakan dan air untuk melembabkan tempat hidupnya (Herlina, 2017). Adanya spesies yang dominan pada suatu habitat menyebabkan nilai Indeks kekakayaan,
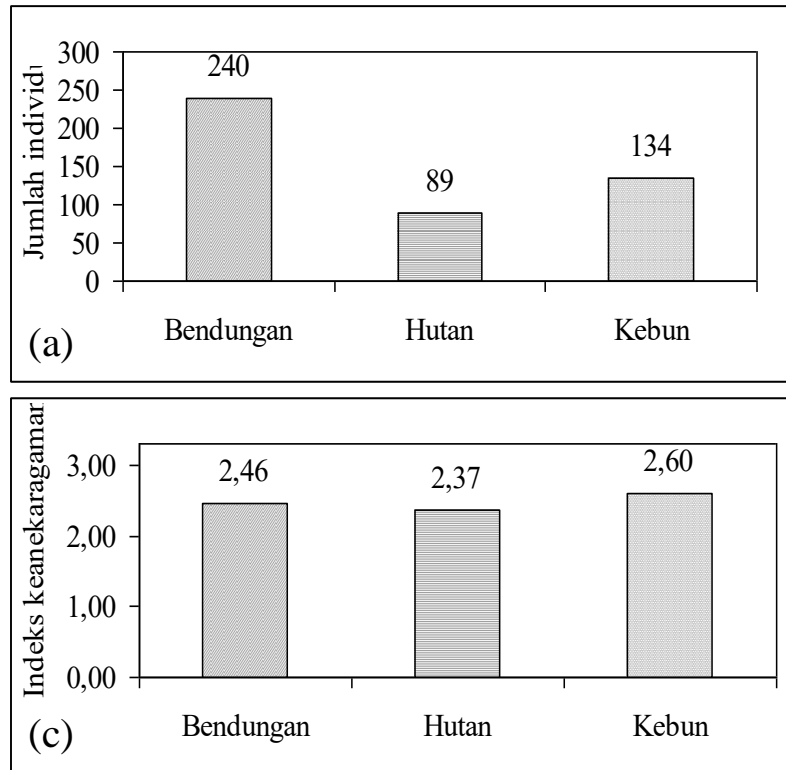

and Bapeamon, 2017). Sharma (2009) melaporkan bahwa terdapat korelasi antara kompleksitas struktur habitat, bentuk vegetasi, dengan keanekaragaman kupukupu. Keanekaragaman vegetasi yang tinggi akan meningkatkan keanekaragaman kupukupu. Komponen daya dukung lingkungan seperti tersedianya habitat, air, mineral, makanan, suhu, dan kelembaban akan berpengaruh terhadap keanekaragaman kupu-kupu (Mas'ud et al, 2018).

Sutra et al. (2012) juga melaporkan bahwa perbedaan vegetasi tumbuhan pada

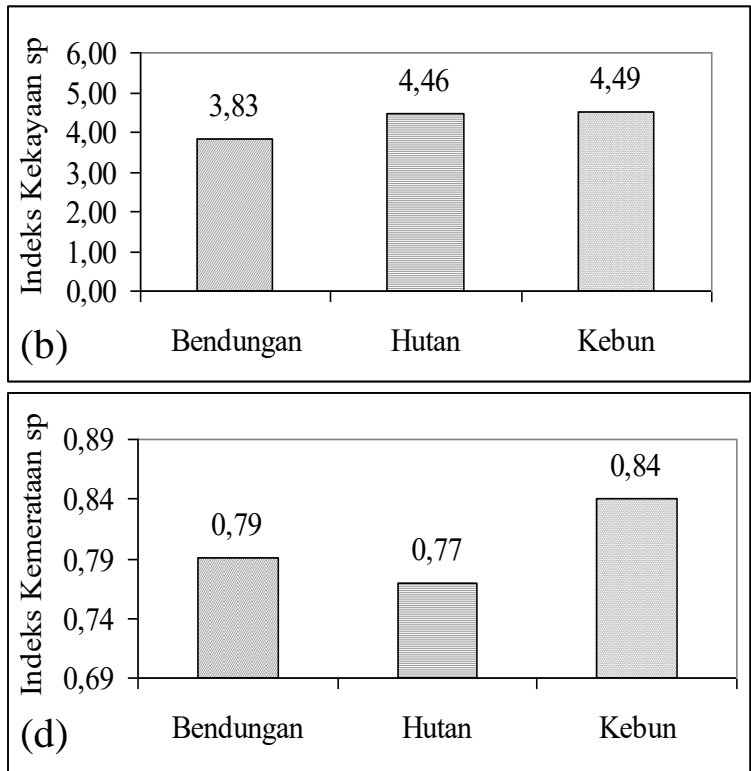

Gambar 2. Jumlah individu (a), indeks kekayaan spesies (b), indeks keanekaragaman (c), dan indeks kemerataan spesies (d) pada tiga tipe habitat di kawasan bendungan Ulung Peliang, Kecamatan Tamako. Kepulauan Sangihe.

indeks keanekaragaman dan indeks kemerataaannya menjadi rendah.

Habitat kebun memiliki indeks kekayaan dan indeks keanekaragaman tertinggi. Hal ini disebabkan karena tidak adanya spesies yang mendominasi pada habitat tersebut. Faktor penyebab lainnya adalah habitat tersebut banyak ditumbuhi oleh beranekaragam tumbuhan sebagai tumbuhan pakan dan tumbuhan inang serta tempat berlindung bagi kupu-kupu.

Keanekaragaman kupu-kupu meningkat dengan meningkatnya skala habitat dan kompleksitas struktur vegetasi (Nkongolo suatu habitat sangat menentukan keanekaragaman jenis kupu-kupu yang ditemukan pada daerah tersebut. Habitat kebun juga terdapat sedikit kanopi dibandingkan habitat hutan. Hal ini memberikan variasi dalam menerima paparan sinar matahari secara langsung. Menurut Hamer et al. (2003) kupu-kupu memiliki perbedaan kesukaan terhadap paparan sinar matahari. Kebun yang sedikit terbuka menghasilkan cahaya dan ruang yang cukup sehingga menarik banyak kupukupu yang datang dibandingkan hutan alami.

Indeks kemerataan spesies tertinggi ditemukan pada habitat kebun. Nilai 
kemerataan yang tinggi untuk tiap habitat menunjukkan tidak ada spesies kupu-kupu yang dominan. Semakin kecil nilai kemerataan spesies, maka penyebaran spesies tidak merata dan terjadi dominasi oleh spesies kupu-kupu tertentu (Magurran, 1988).

Hal ini menunjukkan bahwa pada kebun tidak ada spesies kupu-kupu yang mendominasi. Menurut Rahayuningsih et al, (2012) tingginya indeks kemerataan spesies di suatu habitat menunjukkan bahwa habitat di daerah tersebut lebih stabil dibandingkan habitat dengan kemerataan spesies yang rendah. Kemerataan spesies kupu-kupu yang paling rendah terdapat di pinggir bendungan, menunjukkan bahwa ada beberapa spesies kupu-kupu yang mendominasi dalam jumlah individu per jenis. Hal tersebut dapat ditemukan tiga spesies kupu-kupu yang mendominasi pinggir bendungan diantaranya Eurema tominia, Graphium meyeri dan Junonia hedonia intermedia. Menurut Effendi (2009), semakin besar nilai kemerataan spesies kupu-kupu, maka penyebaran spesies kupu-kupu merata dan tidak ditemukan dominan spesies kupu-kupu tertentu.

\section{KESIMPULAN}

Hasil penelitian kupu-kupu di kawasan Bendungan Ulung Peliang Kecamatan Tamako Kepulauan Sangihe ditemukan sebanyak 30 spesies dan 463 individu dari lima famili kupu-kupu. Spesies yang paling banyak ditemukan adalah Eurema tominia kemudian Junonia hedonia intermedia. Famili kupu-kupu yang dominan ditemukan adalah Nymphalidae. Analisis keanekaragaman didapatkan bahwa indek kekayaan, indek keanekaragaman dan indek kemerataan spesies kupu-kupu tertinggi ditemukan pada habitat kebun, sedangkan kelimpahan spesies tertinggi terdapat pada habitat pinggir bendungan.

\section{DAFTAR PUSTAKA}

Amir MWA, Noerdjito dan Kahono S (2003) Serangga Taman Nasional
Gunung Halimun Jawa Bagian Barat : Kupu (Lepidoptera). BCP-JICA. Bogor.

Bambang P, Muhammad A (2013) Keanekaragaman jenis kupu-kupu di Taman Kehati Unnes. Biosaintifika 5 (5): 101-105.

Dendang B (2009) Keragaman kupu-kupu di Resort Selabintina Taman Nasional Gunung Gede Pangrango Jawa Barat. Jurnal Penelitian Hutan dan Konservasi Alam 6: 25-36.

Effendi MA (2009) Keragaman kupu-Kupu (Lepidoptera: Ditrysia) di Kawasan Hutan Koridor Taman Nasional Gunung Halimun Salak, Jawa Barat. [Tesis]. Program Pascasarjana. Institut Pertanian Bogor.

Hamer KC, Hill JK, Benedick SN, Mustaffa TN. Sherratt, Maryati M, Chey VK (2003) Ecologi of butterflies in natural and Selectively Logged Forests of Northern Borneo: the Importanceof habitat heterogeneity. Journal of Applications of Ecology 40: 150-162.

Herlina S (2017). Kelimpahan kupu-kupu Nymphalidae di Kawasan Air Terjun Parangloe Kabupaten Gowa. [Skripsi]. Universitas Islam Negeri Alauudin Makassar. Makassar.

Koneri R, Saroyo (2012) Distribusi dan keanekaragaman kupu-kupu (Lepidoptera) di Gunung Manado Tua, Kawasan Taman Nasional Laut Bunaken, Sulawesi Utara. Jurnal Bumi Lestari 12 (2): 357-365.

Koneri R, Vera PM (2016) Diversity of butterfly (Lepidoptera) in ManemboNembo Wildlife Reserve, North Sulawesi. Pakistan Journal of Biological Sciences 19 (5): 202-210.

Lamatoa DC, Koneri R, Siahaan R, Mabuaat PV (2013). Populasi kupukupu (Lepidoptera ) di Pulau Mantehage, Sulawesi Utara. Jurnal Ilmiah Sains 13:52-56.

Lestari DF, Putri RDA, Ridwan M, Purwaningsih AD

Keanekaragaman kupu-kupu (Insekta: Lepidoptera) di Wana Wisata Alas Bromo, BKPH Lawu Utara, 
Karanganyar, ( Jawa Tengah. Pros Sem Nas Masy Biodiv Indon 1: 1284-1288.

Magurran AE (1998) Ecological diversity and its measurements. Croom Helm Limited. London.

Mas'ud A, Abubakar A, Chumidach R (2018) Kajian Filogenetik kupu-kupu Papilio Spp berdasarkan sekuen Gen ND5 secara Insiliko. Jurnal Biologi Edukasi Edisi 21. 10: 35-39.

Nkongolo NV, Bapeamoni F (2017). The effect of land use type on butterfly diversity at Masako Forest Reserve, Kisangani, Doemocractic Republic of Congo. Intenational Journal of Biodiversity and Conservation 10 (3): 131-144.

Panjaitan R (2008). Distribusi dan (Superfamili Papilionidae: Lepidoptera) di Minyambou Cagar Alam Pegunungan Arfak Manokwari Papua Barat. Berk Ilm Biol 7: 11-16.

Pareang, G (2018) Keanekaragaman kupukupu (Lepidoptera) di Kawasan Air Terjun Tunan Talawaan Minahasa Utara Sulawesi Utara. [Skripsi]. Universitas Sam Ratulangi Manado. Manado.

Peggie D (2014) Mengenal kupu-kupu. Pandu Aksara Publishing. Jakarta.

Rahayuningsih M, Oqtafiana B, Priyono (2012). Keanekaragaman jenis kupukupu Superfamili Papilionidae di Dukuh
Banyuwindu Desa Limbangan Kecamatan Limbangan

Kabupaten Kendal. FMIPA Universitas Negeri Semarang. Indonesia.

Sari EFW, Soekardi H, Nukmal N, Martinus (2013) Diversty of Nymphalidae in Tegal Island and Puhawang Kecil Island, Lampung Bay; 19-20 November 2013; Lampung, Indonesia. Lampung (ID). 376-385.

Sarma K, Kumar A, Devi A, Mazumdar K, Krishna M, Mudoi P, Das N (2012). Diversity and habitat association of butterfly species in Foothilss of Itanagar, Arunchal Paradesh, India. Zoology 1: 67-77.

Sharma G, Joshi PC (2009) Diversity of butterflies ( Lepidoptera : Insecta ) from Dholbaha dam ( Distt . Hoshiarpur ) in Punjab Shivalik, India. Biological Forum an Inter.Journal 1: 11-14.

Sutra NSM, Dahelmi, Siti S (2012) Spesies kupu-kupu (Rhopalocera) di Tanjung Balai Karimun Kabupaten Karimun Kepulauan Riau. Jurnal Biologi Universitas Andalas 1: 35-44.

Vane-Wright RI, and de Jong R (2003) The Butterflies of Sulawesi : Annotated checklist for a critical island fauna. Zool. Verh. Leiden 343: 3-267. 